\title{
Comunicação
}

\section{A interação médico-cliente}

\author{
E.J. SOAR FILHO \\ Instituto de Cardiologia, Florianópolis, SC.
}

\begin{abstract}
RESUMO - O autor denomina de "interação médicocliente" o conjunto de fenômenos tradicionalmente conhecidos como "relação médico-paciente". A interação médico-cliente é entendida como uma coconstrução, mediada pelos contextos nos quais ocorre e pelas reações emocionais dos agentes envolvidos. $O$ autor discute aspectos relativos aos contextos da interação e sugere algumas medidas que podem contribuir para o estabelecimento de
\end{abstract}

\section{A INTE RAÇÃO PROFISSIONAL DE SAÚDE-CLIENTE}

Estamos todos habituados à expressão "relação médico-paciente", de uso generalizado e significado nem sempre muito claro. Apesar do que há de específico neste conceito, muito daquil o que caracteriza a interação entre o médico e seu paciente é comum a outras práticas de saúde e enquadra-se no campo de fenômenos que denominei, em outro local, de "relação profissional de saúde-cliente"1.

Essa expressão conota, antes de mais nada, a noção de equipe: os vários profissionais das equipes de saúde estão sujeitos a fenômenos psicológicos e interacionais comuns, subjacentes às suas práticas. E m segundo lugar, conota a idéia de que o paciente é sobretudo um cliente, ou seja, um usuário, um comprador de servi ços, qual quer que seja o contexto em que é atendido. De fato, a palavra "paciente" traz implícita a idéia de uma passividade e de uma posição hierarquicamente inferior, que muitas vezes está na origem do fracasso terapêutico.

O termo "paciente" não precisa, entretanto, ser abandonado, mesmo porque é universal mente utilizado. No presente artigo, em respeito à força do uso, e por motivos estilísticos e práticos, serão empregados ambos os termos: clientee paciente. O primeiro será utilizado num sentido mais dirigido ao contexto institucional, assim como para caracterizar uma visão do paciente como sujeito ativo e co-construtor do encontro terapêutico*. Além disso, muitas vezes o

\footnotetext{
* Hollender ${ }^{2}$ propõe uma escala de "atividade-passividade" que tem, num dos seus extremos, as situações agudas, as urgências, os estados de coma ou as cirurgias, nas quais a passividade do cliente é necessariamente maior. No outro extremo estão os tratamentos de
}

uma boa aliança de trabal ho. Por fim, são relacionados e comentados os atributos pessoais do médico e as atitudes terapêuticas desejáveis para uma boa interação médico-cliente, tais como a empatia, a continência, e as capacidades de comunicação e de conotação positiva.

UnITERmos: Relação médico-paciente. Psicologia médica.

cliente (aqui no sentido daquele que busca a ajuda) não é propriamente o paciente (no sentido de quem necessita de tratamento), podendo ser o seu responsável imediato, como nos casos de consultas pediátricas, geriátricas, de emergência etc.

A idéia de participação ativa está subentendida na expressão "interação médico-cliente", introduzida neste trabal ho. O termo "interação", conforme o Dici onári o Aurélio, define uma "ação que se exerce mutuamente entre duas ou mais coisas, ou duas ou mais pessoas; ação recíproca" (grifo meu). Ele refere-se a um processo que ocorre entre dois agentes, mais do que como a ação de um sujeito sobre outro, o que não fica claramente explicitado na palavra "relação".

E ssas questões não são meramente semânticas, uma vez que as denominações propiciam e induzem diferentes maneiras de ol har e de compreender os objetos que nomeados, ou como "construímos" a realidade ${ }^{3}$. Não é por outra razão que a Medicina abandonou o termo "lepra", em favor de "hanseníase", descontaminado dos estigmas que caracterizavam aquele; ou que as nosografias psiquiátricas já não se refiram mais à "histeria", e sim a "transtornos conversivos". E não apenas a denominação tem este poder, mas sobretudo a maneira como os sintomas são organizados ${ }^{4}$ e como são construídas as narrativas, em nosso caso, as "histórias clínicas"5,6.

A interação médico-cliente, quer a chamemos de relação médico-paciente ou de rel ação profissional-

doenças crônicas, nos quais se espera uma maior participação. De forma geral, estarei consi derando aqui o cl iente como um indi víduo em condições, ou com potencial, para uma participação ativa no processo de cura. 
cliente, pressupõe, como em todas as relações humanas, a existência de um contexto. O contexto é o que a configura, estabel ece seus limites e possibilidades e determina os papéis e funções dos participantes. Ao mesmo tempo, essa interação está sujeita à ocorrência de triangulações ${ }^{7,8}$.

Andol $\mathrm{fi}^{7}$ afirma que o triângulo é a unidade mínima de observação, quando se trata de compreender as relações interpessoais. Assim, praticamente não se pode falar do encontro entre o médico e seu cliente como algo em abstrato, como um processo isolado e descontextualizado entre duas pessoas. A rigor, deveríamos falar em relações médico-enfermidade-cliente, ou médico-família-cliente, ou ainda médico-instituição-cliente, e assim por diante.

1) Triangulação médico-enfermidade-cliente: nesse processo estão envol vi dos fenômenos psíqui cos, como sentimentos e fantasias (geralmente inconscientes), acionados pela enfermidade e pelos vários aspectos a el a associados (vivências pregressas, história familiar, identificações com pessoas significativas, medos específicos, etc.). Como veremos adiante, diante do desconhecido é normal que o indivíduo, e aqueles que o rodeiam, crie fantasias e reaja emocionalmente a elas.

Não apenas o cliente está sujeito a esses fenômenos, mas também o médico, que por vezes tem que se defrontar com doenças impregnadas de forte carga simbólica. Por exemplo, pode ser difícil a um médico atender um caso de infarto agudo do miocárdio pouco tempo depois de perder um familiar importante, como o próprio pai, devido à mesma doença; ou a um psiquiatra tratar de uma depressão desencadeada por luto, quando ele próprio está elaborando a perda de um ente querido. Tais vivências internas podem ser comprometedoras, sobretudo quando o médico não estiver consciente da possibilidade de que os sentimentos interfiram em suas habilidades profissionais. Por outro lado, se estiver ciente del as e for capaz de elaborálas adequadamente, pode transformar suas próprias vivências interiores em instrumentos de empatia e compreensão.

Além disso, a doença pode ser fonte de gratificações para o paciente, quer sejam estas gratificações entendidas como "ganhos secundári os", quer sejam entendidas como "função do sistema familiar". E m um caso ou no outro, as resistências e boicotes do cliente (paciente e familiares) ao tratamento podem ser fonte de grande insatisfação para o médico. Dependendo das características de personal idade deste, tais reações podem ser vivenciadas como um desafio à própria competência ou autoridade, o que só tornará mais difícil seu manejo.

Ao falarmos em função do sistema familiar, já entramos no campo de outro tipo de triangulação:

2) Triangulação médico-família-cliente: sabemos todos, ainda que de forma meramente intuitiva, da importância desempenhada pela família tanto na gênese quanto na resolução dos problemas médicos. O campo das terapias sistêmi cas de família tem proporcionado instrumentos de compreensão e manejo dos fenômenos familiares implicados no adoecer e na cura ${ }^{8-10}$.

O médico - e seus intentos terapêuticos - pode ser encarado pela família como uma séria ameaça à homeostase do sistema familiar. Quando a doença desempenha uma função importante na dinâmi ca da família, sem que o médico entenda a natureza dessas "resistências" e sem que possa negociar as mudanças com a família, toda tentativa de tratamento acaba frustrada. É preciso reconhecer, nessas situações, o papel adaptativo e comunicacional dos sintomas e tolerar a necessidade do cliente (paciente e familiares) de mais tempo para realizar mudanças e estabelecer novos padrões comportamentais.

Além disso, a família é, no mais das vezes, um fator indispensável de suporte e colaboração ao tratamento, sendo insubstituível como fonte de segurança e afeto ao paciente. Caberá ao médico reconhecer suas próprias limitações (limitações do seu conhecimento e da sua importância na vida do cliente) e valorizar a participação dos familiares, fazendo-os aliados e colaboradores do processo terapêutico.

Aqueles que trabalham em alguma instituição de saúde - virtualmente todos os médicos, nos nossos dias - entenderão sem dificuldades o que denomino de

3) Triangulação médico-institui ção-cli ente: também aqui, as interações podem ser de natureza "positiva" ou "negativa" para o encontro terapêutico. Pode ser benéfico à interação médico-cliente uma atribuição, intermediada pela instituição, de sentimentos e expectativas positivos em relação ao profissional: o cliente, ao buscar um serviço conceituado, do qual já tenha obtido boas referências, geralmente depositará no médico essas expectativas e se encontrará numa disposição básica de maior aceitação e cooperação. Também o médico pode ter sua disponibilidade interior aumentada em função das condições de trabal ho e da remuneração que recebe: é comum a designação de "paciente diferenciado" para os clientes que remuneram melhor o trabal ho médico, os quais, muitas vezes, são atendidos mais prontamente e com maior cortesia.

Por outrolado, são comuns as situações em que o médico se torna, perante o cliente, um depositário da frustração e da raiva produzi das pela instituição, 
ao ser visto como um vilão, representante direto de um sistema de saúde incompetente e desumano. Por fim, pode também dirigir sobre o cliente sua hostilidade pelos maus salários recebidos ou pelas más condições de trabalho a que está sujeito.

Como em outras esferas da vida, entretanto, os extremos facilmente se encontram, e palavras como "positivo" e "negativo" podem provocar mais confusões do que esclarecimentos. Assim, a admiração que o cliente nutre por seu médico pode transformar-se num problema, quando se reveste de um caráter excessivamente idealizado e carregado de expectativas mágicas. Por outrolado, existe um aspecto desejável - que devemos aprender a val orizar devidamente - numa ati tude menos conformista e resignada diante das frustrações e maus tratos causados por instituições de saúde (leia-se sus, planos de saúde inescrupulosos, clínicas de tratamentos charlatanescos, etc.). A expressão das insatisfações e da indignação do cidadão será a contrapartida de uma participação mais ativa e consciente por parte do cliente.

Como se pode antever, a complexidade da interação médi co-cl iente requer uma abor dagem multidimensional e interdisciplinar que não cabe num único artigo. Essa relação pode ser entendida a partir de diversos pontos de vista, como o políticoideológico, o deontológico e o psicológico.

F ocalizo, a seguir, algumas questões relacionadas à "psi col ogi a" da inter ação médico-cliente, procurando abordar alguns dos fenômenos de natureza propriamente intrapsíquica (para o que o referencial psicanalítico nos fornece os conceitos fundamentais) e interacional (procurando utilizar alguns conceitos do campo da teoria sistêmica), tendo sempre em vista que tal divisão é apenas teórica e que as abordagens podem ser utilizadas de forma complementar, e não excludente.

Procuro não perder de vista as relações entre esses aspectos "psicológi cos" e as dimensões "ideológi cas" e "éticas" da interação. O objeti vo final é o de propor algumas características contextuais desejáveis para essa interação e sugerir alguns atributos desejávei s no médi co para o estabeleci mento de uma boa relação terapêutica.

\section{AS REAÇÕES EMOCIONAIS}

Os probl emas agudos são mais propícios à observação das reações emocionais dos clientes (e dos médi cos) diante da doença e do desconhecido. Além disso, essas situações nos permitem pensar como o cliente se apresenta à instituição e ao profissional de saúde, e que tipo de vínculo estes I he propõem.

Por exemplo, como se sente uma jovem mãe que leva seu primeiro bebê a um pronto-socorro com febre, diarréia e sinais de desidratação? Podemos supor que venha muito assustada, confusa e repleta de fantasias atemorizantes sobre o que possa estar acontecendo. É também muito provável que traga, intimamente, sentimentos de culpa e de vergonha relacionados à doença de seu filho.

Vista sob o prisma de suas reações emocionais, segundo um referencial psicodinâmico, pode-se afirmar que essa mãe está emocional mente "regredida". Diante do desconhecido, de situações estressantes, detensão emocional, e sobretudo diante da dor e das limitações físicas, é uma tendência normal do ser humano reagir com algum grau de regressão, ou seja, retornar a modos desentir, de pensar e deagir próprios às fases infantis do desenvol vimento.

No estado de regressão, a pessoa doente - assim como os seus familiares - tem necessidades de tranqüil ização e apoi o equival entes às de uma criança em relação à mãe. Infelizmente, por falta de preparo ou de amadurecimento pessoal, nem sempre o médico está capacitado para fornecê-Ios. Em outras palavras, nem sempre ele é continente para a ansi edade do cl iente (em nosso exemplo, a mãe do bebê). Diante das dificuldades, ou daquilo que aos seus ol hos está "errado", é freqüente que o profissional assuma uma atitude repreensiva e autoritária, através da qual busca, por sua vez, li dar com os seus próprios sentimentos de ansiedade perante o sofrimento e os riscos de "fracasso".

$\mathrm{Na}$ situação que nos serve de exemplo, uma atitude desse tipo, como uma crítica severa pela demora em buscar o serviço médico, ou por alguma outra conduta considerada inadequada, pode incrementar as angústias e cul pas da mãe, reduzi ndo com isso ainda mais suas capacidades de entender e reter as orientações que Ihe estão sendo transmitidas, com o que, muitas vezes, se mantém o problema num ciclo vicioso.

O grau de regressão do cliente, ou o prejuízo à utilização dos próprios recursos, pode variar de acordo com pelo menos três fatores da interação médico-cliente:

a) as características de personalidade: são especialmente suscetíveis as pessoas com traços mais dependentes, com tendências hipocondríacas, e com dificuldades de entrar em contato com seus próprios sentimentos: aqueles pacientes que a psicanálise nos tem ensinado a pensar em termos de "personalidades narcísicas", ou seja, inseguras em relação aos aspectos da própria identidade e, portanto, com maior tendência a sofrer danos à autoestima. Não nos esqueçamos que um médico excessivamente narcisista também está mais sujeito a reagir de forma impaciente e/ou autoritária, em 
resposta a certos comportamentos dos clientes vi venciados como um desafi o a ele (médico) e ao seu conhecimento do mundo;

b) a qualidade da informação sobre a natureza do problema e sobre os procedimentos real izados: o cliente, como já vimos, geralmente vem com uma enorme carga de temores provocados pelo desconhecimento sobre a possível origem dos sintomas, agravados - especialmente no caso dos clientes institucionais - pelo desconhecimento sobre quem, e como, vai atendê-lo. Ele chega ao serviço médico, geralmente, sem saber quanto tempo terá que aguardar e se o profissional que o atenderá tem a necessária competência (e paciência). Também o desconhecimento sobre os procedimentos diagnósticos e/ou terapêuticos aos quais é submetido pode ser fonte de intensa ansiedade; e

c) a forma como a institui ção e o médico o rece bem e respondem às suas demandas: se o cliente é colocado numa posição que o infantiliza ainda mais, intensifica-se a regressão e reduz-se a possibilidade de contar com sua efetiva partici pação na tarefa terapêutica. A esse propósito, há um interessante depoi mento do diretor de cinema F ederico Fellini, numa das últimas entrevistas que concedeu, sobre sua condição de doente internado num hospital para recuperação de um acidente vascular cerebral que o deixou hemi plégico:

Durante meses você é inserido em lugares aparentemente protetores, com hierarquias, histeria e acessos de raiva que não são seus, num vórtice de dias que não são seus. Você é tratado como um jogador de futebol: “Vamos lá, não desista. Você tem que conseguir. Onde está sua coragem? Você precisa cooperar, vamos lá...". Ou então como se fosse um bebê: "Agora eu quero que você venha e pegue este lápis com sua mão esquerda...". E você não consegue fazer nem isso. [...] Você é mergulhado num ambiente infantil, de berçário. "Agora vamos lavar nosso rosto. Será que queremos um pouco de queijo em nossa sopinha? Agora vamos tomar nosso comprimido, nosso comprimido para dormir, nosso tranqüilizante." Mas o único "eu" nesse "nós", o único que é obrigado a lutar e sofrer, é você mesmo. A doença torna você dependente. Essa dependência faz você regredir à infância. (Entrevista a Lietta Tournabuoni [La Stampa], publicada pelo jornal Fol ha deS. Paulo, 1o de novembro de 1993).

Simultaneamente aos aspectos "regressivos", todo cliente mantém preservadas áreas de funcionamento psíquico que são adaptativas. Esses aspectos maduros da personalidade são fundamentais para o estabelecimento de uma aliança de trabalho com profissional de saúde, aliança esta imprescindível à realização da tarefa comum**. O médico deve estar pronto a responder, portanto, às demandas regressivas, sem, no entanto, intensificá-las, ao mesmo tempo em que tenta reforçar a parte potencial mente capaz de manter níveis superiores de funcionamento.

As reações emoci onais que permeiam e configuram a interação médico-cliente necessitam ser minimamente compreendidas pelo médico (seria desejável que essa compreensão fosse emocional, mais do que meramente intelectual, adquirida através de alguma experiência de terapia pessoal). Entre os fenômenos associados à regressão psíquica do paciente estão os mecanismos internos de defesa, os quais devem ser respeitados como formas necessárias de adaptação ao estresse, pelo menos até que, com o auxílio da equipe de saúde, outros recursos possam ser mobilizados ${ }^{12-14}$ :

1) Transferência: o conceito psicanalítico de transferência refere-se ao conjunto de reações que o paciente apresenta em relação ao analista ao colocá-lo no lugar de uma das pessoas significativas de sua vida (como pais, irmãos e cônjuges), vivenciando na rel ação com o terapeuta - "transferindo" para ele - emoções originárias das relações com aquelas pessoas. Os fenômenos transferenciais, lato sensu, estão presentes em todas as relações humanas e, sendo assim, também na relação médi co-cliente. Podemos nos referir com este termo, por exemplo, ao conjunto de expectativas mágicas e onipotentes depositadas no médico e às reações infantis perante às inevitáveis frustrações de tais expectativas.

A transferência, segundo a teoria psicanalítica, refere-se aos aspectos mais infantis, ou "neuróticos", da rel ação terapêutica, enquanto a aliança de trabalho, ou aliança terapêutica, se estabelece entre os aspectos mais amadureci dos eadaptativos de cliente e do médico.

2) Produção de fantasias: diante do desconhecido, o ser humano cria hipóteses para preencher o conhecimento que Ihe falta. Muitas vezes as teorias, ou fantasias, que o cliente cria sobre sua enfermidade são incrementadas pela regressão, assumindo formas muito assustadoras. Os fantasmas fabricados pela mente, nos casos de doenças, atendem por nomes como "AIDS", "câncer", "meningi te", "infarto", etc. Quem já não atendeu um paci ente com crises de pânico, vivenciadas com o pavor diante da morte iminente? Muitas vezes, com o

\footnotetext{
** A expressão aliança de trabalho designa a capacidade de o paciente estabelecer um víncul o suficientemente forte para superar as vicissitudes do tratamento (transferência, resistências, decepções, etc.), baseado na motivação e na disposição racional e consciente em cooperar com o tratamento ${ }^{11}$
} 
propósito consciente de esclarecer o paciente, e outras tantas com o propósito inconsciente de exibir todo seu conhecimento, colocando-se numa posição muito superior à do cliente, o médico pode incrementar ainda mais essas fantasias primitivas. Isso pode ocorrer quando expressa precocemente - e desnecessariamente - hipóteses diagnósticas de doenças graves.

De um ponto de vista prático, o conhecimento desse fenômeno sugere-nos sempre perguntarmos ao paci ente quais as teorias que el e tem a respeito do que está acontecendo. Se o profissional mostrase aberto a ouvir as fantasias do cliente de forma não preconceituosa ou jocosa, terá uma maior possibilidade de aliviar suas ansiedades e de se conectar os seus aspectos mais adultos e colaborativos.

3) O mecanismo da negação: entre os vários mecanismos de defesa envolvidos na relação do sujeito com a doença - e com o profissional de saúde - este talvez seja aquele capaz de provocar as conseqüências mais importantes. Existem pessoas que percebem a doença, as limitações ao seu desempenho habitual, ou mesmo a dúvida ou desconhecimento, como coisas vergonhosas, como falhas de caráter (este é também o caso das "personalidades narcísicas").

Pessoas que baseiam todo o amor próprio sobre determinados atributos físicos poderão ter maior dificuldade para lidar com limitações que atinjam essas áreas. Um homem jovem e desportista, por exemplo, que tem seu vigor físico subitamente afetado por uma doença cardíaca, poderá reagir a isto com tentativas, mais ou menos inconscientes, de negar a doença. U ma reação bastante comum, relacionada a esse mecanismo, manifesta-se no comportamento de oposição sistemática a todas as medidas terapêuticas que possam atestar a existência do problema. Assim, o paciente mantém, eàs vezes incrementa, o hábito de fumar, não segue as recomendações dietéticas e medicamentosas, e passa a desenvolver comportamentos de risco.

4) Ganho secundário: este conceito já é relativamente conheci do da maioria dos médi cos e se refere às vantagens ou benefícios obtidos através dos sintomas, de exames, ou da condição de enfermo de uma forma geral. São relativamente freqüentes os casos de pessoas que, em função de seus problemas de saúde, passam a deter um enorme poder no interior das relações familiares, mantendo com isso muitos privilégios pessoais. Os ganhos secundários são, de fato, um importante fator de resistência ao tratamento. Quem já não atendeu "aquela senhora poliqueixosa" que, apesar das queixas e do sofrimento real, boicota os intentos terapêuticos, conseguindo com isso atenções especiais da família.
Podem, também, ocorrer boi cotes ao tratamento por parte dos familiares, como expressão do temor às mudanças nos padrões interacionais da família.

U ma forma comum de ganho secundári ó aquele que tem uma função comuni cati va, ou seja, o uso do sintoma, da não mel hora ou do sistemático boi cote às medidas terapêuticas, como forma de expressar sentimentos como a raiva do marido, do patrão e mesmo do médico ou da instituição. Os mesmos recursos poderão ser utilizados, outras vezes, como forma de pedir ajuda, ou de expressar sentimentos que o paciente não pode tolerar na consciência, nem tampouco verbalizar, como carência afetiva, desamparo, insegurança, etc.

Todas essas reações emocionais do cliente podem representar dificuldades ao estabelecimento de uma aliança de trabalho com o médico. Este também, por sua vez, está sujeito a apresentar reações contratransferenciais e contra-resistências ${ }^{* * *}$. Blaya ${ }^{12}$ e Zimer man ${ }^{14}$ chamam especial atenção para o fato de que médicos que apresentam traços excessivamente narcisistas de personalidade reagem mal às necessi dades primitivas dos pacientes, epara orisco de estabel ecerem conlui os com os aspectos regressivos do cliente para sua própria gratificação.

Cabe ao médico tentar compreender o senti do que a doença adquire para cada cliente e em cada contexto familiar, sem o que será mais difícil promover a mobilização de recursos terapêuticos necessários à mudança dos padrões comportamentais estabelecidos. Num primeiro momento, poderá ser imprescindível que o profissional atenda às demandas mais dependentes e primitivas do paciente, até que se estabeleça uma sólida relação de confiança e cooperação entre ambos. Mas se essas demandas continuam sendo sistematicamente atendidas de forma paternalística, isso poderá contribuir para a manutenção de um tipo de vínculo de dependência para com o profissional e/ou a instituição $0^{4,12,14}$.

A variedade de fenômenos psicológicos envolvidos nos processos de adoecimento e de tratamento contra-indica a adoção de padrões rígidos de conduta. Não há uma fórmula válida para todos os clientes e situações, apenas a possibilidade de o médico manter uma disposi ção, ou um conjunto de atitudes, que pode contribuir para o estabelecimento de uma boa aliança de trabalho.

A seguir, são comentados dois conjuntos de fatores fundamentais para o estabel ecimento da al iança

\footnotetext{
*** A partícula "contra" não deve ser entendida no sentido de uma reação "contrária", ou como uma forma de oposição. Segundo a teoria psicanalítica, contratransferência e contra-resistência são as contrapartidas no analista (e no médico) dos fenômenos apresentados pelo paciente, constituindo-se nas respostas, em grande parte de natureza inconsciente e não deliberada, a esses.
} 
terapêutica. O primeiro refere-se aos fatores envolvidos na constituição de um contexto propiciador de diál ogo e cooperação, marcado pelo respeito ao cliente enquanto pessoa e cidadão. O segundo referese às qualidades, ou atributos, necessários ao médico para a consecução desse objetivo. Esses elementos são sobrepostos e complementares, e sua dissociação somente se justifica por motivos didáticos.

\section{A CONSTRUÇÃO DO CONTEXTO}

Por meio dos processos de intercâmbio social, mediados pela linguagem, não apenas denominamos mas, sobretudo, construímos a realidade. Assim, as maneiras pel as quais designamos as coisas e as pessoas são ao mesmo tempo produto e produtoras dos modos diversos pelos quais podemos nos relacionar com o mundo e no mundo. É por meio da comunicação em geral (o que inclui a comunicação não-verbal), mas principalmente dos processos lingüísticos - da verbalização - que construímos a interação médico-cliente.

A linguagem, entretanto, não ocorre independentemente dos contextos de comunicação, que são também produtores de significados. As instituições - assim como os profissionais isoladamente - designam seus clientes mediante os contextos em que os atendem. Assim, se quisermos entender como a noção de "cliente" é construída e mantida, devemos perguntar-nos sobre a posi ção reservada ao cl iente, o seu lugar, na instituição (clínica, consultório, etc.)?

A preservação, ou a recuperação, das áreas de funci onamento adulto, mesmo diante da doença ou da incapacitação, depende sobretudo do estabel ecimento de uma interação na qual o cliente seja também "adulto" do ponto de vista de sua cidadania. Ser colocado numa interminável fila de espera ou numa sala superlotada de pacientes, sem conforto, constitui não apenas um ataque brutal à auto-esti ma da pessoa, mas sobretudo à sua identidade de cidadão (no sentido dos seus direitos assegurados à saúde e aos servi ços médicos), constituindo um contexto indutor de regressão psíquica.

Alguns aspectos relacionados ao estabel ecimento de contextos mais favoráveis a uma relação médico-cliente baseada na cooperação e no desenvolvimento conjunto da tarefa terapêutica serão citados a seguir. Muitos deles parecerão óbvios - e de fato o são -, mas serão citados pelo simples motivo de que, interessados que estamos em construir as melhores hipóteses diagnósticas e propor as terapêuticas mais adequadas, nem sempre prestamos suficiente atenção a detal hes aparentemente pequenos que podem trazer grande impacto sobre os resultados de nosso trabalho: 1) atender com hora marcada e com o menor tempo possível de espera; 2) oferecer um espaço de atendimento confortável e que preserve a privacidade; 3) tratar o cl iente pel o nome; 4) ol har o cli ente enquanto conversa com el e; 5) tentar ouvir mais do que falar; 6) comuni car-se com o cl iente em termos compreensíveis a ele, mantendo-o informado sobre seus problemas e sobre os procedimentos realizados; 7) falar sobre o cliente, com outros profissionais, de forma respeitosa e positiva.

Alguns comentários sobre os últimos três itens podem justificar a el aboração dessa lista de sugestões. Os problemas relacionados à comuni cação são bastante generalizados, e podem ser encontrados mesmo em países onde a qualidade dos serviços médicos é supostamente superior ao nosso meio. Boltanski $i^{15}$ realizou uma pesquisa sobre consultas de pediatria na periferia de Paris, na qual constatou que, de todas as palavras pronunciadas durante as consultas, uma média de $83 \%$ eram ditas pelo médico. Destas, $48 \%$ eram perguntas à mãe e apenas $3 \%$ respostas. Esses dados sugerem uma relação médico-paciente excessivamente hierarquizada e pouco propiciadora do diálogo.

Além disso, o discurso médico pode constituir-se numa forma bastante ostensiva de diferenciação cultural e de status social: o uso de terminologia técnica inacessível a não-iniciados, que pode incluir palavras para nós corriqueiras, como "edema", "cefal éia" e "sutura", mas que são desconhecidas para a maioria das pessoas. De pouco vale, entretanto, um paciente subserviente que está, ao mesmo tempo, infantilizado pela falta de conhecimento, paral isado pel as fantasias com que substitui este conhecimento, e incapaz de seguir adequadamente instruções que Ihe foram transmitidas de forma pouco compreensível. Cabe ao médico levar em consi deração não só as limitações intel ectuais e educacionais dos clientes, mas também respeitar as possíveis diferenças culturais, muitas vezes confundidas, de forma preconceituosa, com ignorância.

Final mente, a forma pela qual nos referimos a um cliente para outro profissional contribui não só para a maneira pela qual este virá a se relacionar com o cliente, mas também para a cristalização de estereótipos ligados a ele. Expressões bastante comuns, como "písico", "piti", ou mesmo "poliqueixoso", podem ter efeito devastador sobre as futuras relações do profissional com o cliente. Procurar definir o cliente através de seus aspectos positivos e de suas funções mais adaptativas contribui também para nossa capacidade de nos conectarmos (e de o conectarmos) com esses aspectos na relação terapêutica.

Podemos incluir aqui, também, o hábito relativamente disseminado de se referir a pacientes pelo 
diagnóstico (a "hepatite" da enfermaria x) ou pelo procedi mento real izado (o "cateterismo" do leito y), que contribui ainda mais para a despersonalização já induzida pelo próprio ambiente hospitalar e institucional em geral.

Além desses aspectos gerais do contexto comunicacional, uma das maneiras mediante as quais podemos potencializar os recursos do cliente é incluí-los como elementos da entrevista. Podemos, assim, investigar quais os recursos com que ele próprio dispõe para enfrentar seus problemas de saúde e quais suas expectativas quanto ao tratamento. Alguns exemplos de questões que podem ser formuladas com esses objetivos:

- como tem feito para lidar com o problema até aqui?

- o que funcionou bem e o que piorou o problema?

- como sol ucionou o probl ema em vezes anteriores?

- quem tem ajudado, entre as várias pessoas de seu convívio, e de que forma?

- o que imagina que possa ocorrer como conseqüência desse problema?

- o que imaginou que seria necessári o fazer para resolver o problema?

Sabemos bem que nem sempre o cliente tem condi ções de responder a todas essas perguntas, ou o faz de acordo com o model o cultural mente dominante, e já introjetado, de relação médico-paciente: "espero que o senhor resolva o meu problema!". Mas é também verdade que quase sempre já vem com alguma expectativa de que este ou aquele exame complementar seja solicitado (em psiquiatria, principalmente nos ambulatórios públicos, é comum o pedido por radiografias da cabeça e el etroencefalogramas), ou que determinada medicação seja prescrita (as conheci das "vitaminas"), a respeito do que cabe ao profissional esclarecer, mais do que simplesmente atender.

\section{OS ATRIBUTOS DO MÉ DICO E AS ATITUDES TERAPÊ UTICAS}

O que vimos acima nos conduz à elaboração de um conjunto de qualidades desejáveis para o que ocorra, na interação médico-cliente, uma forte e produtiva aliança de trabalho. Essas qualidades os atributos desejáveis ao profissional de saúde em geral - são propiciadoras das necessárias atitudes terapêuticas. Atributos e atitudes confundem-se e interdeterminam-se, e já foram de certa forma antecipados na seção anterior deste artigo, sobre a constituição do contexto terapêutico.

Como o objetivo deste trabalho é o de sistematizar um conhecimento já mais ou menos difundido, con- sidero útil relacionar e definir - segundo meus próprios critérios e experiência - alguns desses atributos. Vários del es foram propostos por autores, tanto de tradição psicanalítica ${ }^{13,14}$ quanto sistêmica7:

a) empatia: como diz a etimologia do termo (do grego: em-pathos), significa a capacidade de colocar-se no lugar do outro, de compreender o seu sofrimento, suas angústias e dúvidas, sem, no entanto, confundir-se com ele;

b) conti nência: este atri buto diz respei to à capaci dade de conter, ou seja, tolerar dentro de si, toda a carga de pensamentos e sentimentos (alguns culturalmente percebidos como "negativos") que o cliente possa expressar durante o atendimento, sem revides e retaliações. Aí se incluem o choro, a raiva, as dúvidas, as fantasias, os ataques e boicotes ao tratamento, etc.;

c) humildade: a palavra é utilizada aqui não no sentido de uma autodepreciação diante do cliente, mas como sinônimo da capacidade de reconhecimento, pelo médico, de suas limitações humanas e profissionais; assim como de respeito às verdades e crenças do cliente. Este atributo confunde-se, portanto, com o seguinte:

d) respeito para com as diferenças: ter respeito para com cliente significa não se investir do que Balint ${ }^{4}$ denominou de "a função apostólica" do médico, ou seja, sua tendência a se fazer portador de verdades morais supostamente universais e válidas para seus pacientes.

U ma atitude de respeito significa, também, não desqual ificar as queixas do paciente: uma conduta relativamente comum é a de afirmar, quando os sintomas não parecem ter uma clara origem orgânica, que "isso não é nada... é só nervos!". Essa resposta está associada à crença de que um malestar, para ser real, não pode ser de natureza emocional, ou mesmo psiquiátrica;

e) curiosidade: estar aberto ao permanente questi onamento das próprias hipóteses, e às hipóteses construídas pelo cliente, constitui um atributo fundamental para o médico. A curiosidade é fundamental para uma atitude que Andol $\mathrm{fi}^{7}$ denomina de "a dúvida como modalidade de compreensão" (o autor refere-se a um contexto de terapia psicológica, mas sua transposição à interação médico-cliente é perfeitamente possível);

f) capacidade de conotar positivamente: este atributo refere-se à disponibilidade interna para buscar novos sentidos para os comportamentos ${ }^{6}$, nos quais fiquem ressaltados os seus aspectos adaptativos e socialmente valorizados (o que não deve implicar na perda da continência para com os aspectos regressivos). Por exemplo, se o cliente, na impossibilidade de entrar em contato com o médico, 
deixa de usar a medicação em função do aparecimento de um novo sintoma, é preciso que nos lembremos de valorizar sua tentativa de contribuir para a cura, antes de criticá-lo, caso sua decisão não tenha sido a mais acertada, aos nossos ol hos ${ }^{* * * *}$.

g) capaci dade de comunicação: este item referese à competência para o estabelecimento de uma comunicação efici ente, ou seja, a capaci dade de captar nexos comunicativos e de comunicar as próprias hipóteses, dentro de um ambiente de respeito para com as diferenças culturais que separam médico e cliente. Ela deve incluir não apenas os aspectos da comunicação verbal, mas também a habilidade de perceber e decodificar a comunicação corporal do paciente e de interagir a esse nível com ele.

A esses atributos podem ainda ser agregados outros tantos - desejáveis nas pessoas em geral mas princi pal mente naquel as quelidam com o sofrimento humano, como amor à verdade, fl exibilidade, criatividade, paciência e, sobretudo, solidariedade.

$\mathrm{Na}$ falta de muitas dessas características, ou na presença de traços psi copáti cos na personalidade do médico, estaremos diante do que se pode denominar de "patologias da relação médi co-paciente". Zimerman ${ }^{14}$ chama a atenção para a for mação de "conluios inconscientes", que consistem em um tipo de vínculo que complementa as necessidades "neuróticas", ou seja, mais regressivas, deambos - médico e paciente. U m exemplo bastante banal disto encontra-se no hábito de distribuir amostras grátis de medicação, muitas vezes desnecessárias, pelo simples motivo de com isto satisfazer o desejo do paciente de ser provido paternal isticamente de cuidados, e o desejo inconsciente do próprio médico de satisfazer suas necessidades narcísicas de admiração. Quando o profissional se vale conscientemente de seu poder para a obtenção de qualquer vantagem pessoal, como aquelas de natureza pecuniária ou sexual, Zimerman chama a isso de "pactos corruptos".

A menção a esses problemas da interação médico-cliente tem por objetivo de chamar a atenção para aquil o que Balint ${ }^{4}$ já afirmou no seu clássico livro, e que devemos todos ter em mente: que o remédio mais usado em medicina é o próprio médico, o qual, como os demais medicamentos, precisa ser conhecido em sua posologia, reações colaterais e toxicidade.

\section{SUMMARY}

\section{The client-doctor interaction}

The author relabels the traditional concept of "pati ent-doctor relati onshi p" as "client-doctor interaction", which is revi ewed as part of a larger group of phenomena called "health professional-client interactions". The main emotional reactions in this interaction are discussed, as well as the context in which happen. Some procedures in order to establish a good work alliance with the client, and make some remarks about the desirable personal attributes of the doctor are suggest. [Rev Ass Med Brasil 1998; 44(1): 35-42.]

KEY WORDS: Patient-doctor relationship. Medical psychology.

\section{REFERÊ NCIAS BIBLIOGRÁFICAS}

1. Soar Filho EJ . Relação profissional de saúde-cliente. Arq Cat Med 1994; 23: 185-9.

2. Schneider PB. Psicologia aplicada a la practica médica. Buenos Aires, Editorial Paidos, 1974.

3. Berger PL, Luckmann T. A construção social da realidade. 12a ed. Petrópolis, Vozes, 1995.

4. Balint M. O médico, seu paciente e a doença. Rio de J aneiro, Atheneu, 1988.

5. Sluzki CE. Cibernética y terapia familiar: un mapa mínimo. Sistemas Familiares 1987; agosto: 65-9.

6. Sluzki CE. Transformations: a blueprint for narrative changes in therapy. Fam Proc 1992; 31: 217-30.

7. Andolfi M. A linguagem do encontro terapêutico. Porto Alegre, Artes Médicas, 1996.

8. Hoffman L. Foundations of family therapy. New York, Basic Books, 1981.

9. Andolfi M, Angelo C, Menghi P, Nicolo-Corigliano AM. Por trás da máscara familiar. $3^{a}$ ed. Porto Alegre, Artes Médicas, 1989.

10. Minuchin S, Fishman HC. Técnicas de terapia familiar. Porto Alegre, Artes Médicas, 1990.

11. Greenson RR. A técnica e a prática da psicanálise. Rio de J aneiro, Imago, 1981.

12. Blaya M. A relação médico-paciente. Rev Psiquiat Dinâmica 1967; 7: 52-65.

13. Tähkä V. O relacionamento médico-paciente. Porto Alegre, Artes Médicas, 1986.

14. Zimerman DE. A formação psicológica do médico. In Mello FilhoJ ed. Psicossomática hoje. Porto Alegre, Artes Médicas, 1992.

15. Boltanski L. As classes sociais e o corpo. Rio de J aneiro, Graal, 1979.
**** U ma cliente, ao justificar sua preferência pela medicina homeopática, foi categórica ao afirmar que nessa abordagem "aquil o que acontece é visto como uma necessidade do corpo, como al go que tem função. A al opatia sempre vê tudo como doença...". O que faz o médico homeopata em relação aos sintomas físicos assemel hase à conotação positiva dos comportamentos sintomáticos nas terapias familiares. O fato de que um grande número de pacientes tenha migrado, nos últimos anos, para formas não convencionais de medicina, ou para a chamada "medicina popular", parece também indicar a importância que tem, para além dos fundamentos doutrinais, o respeito às formas de comunicação e às crenças culturalmente dominantes. 